\title{
Enzyme promiscuity: using the dark side of enzyme specificity in white biotechnology
}

\author{
Benu Arora', Joyeeta Mukherjee ${ }^{1}$ and Munishwar Nath Gupta ${ }^{2 *}$
}

\begin{abstract}
Enzyme promiscuity can be classified into substrate promiscuity, condition promiscuity and catalytic promiscuity. Enzyme promiscuity results in far larger ranges of organic compounds which can be obtained by biocatalysis. While early examples mostly involved use of lipases, more recent literature shows that catalytic promiscuity occurs more widely and many other classes of enzymes can be used to obtain diverse kinds of molecules. This is of immense relevance in the context of white biotechnology as enzyme catalysed reactions use greener conditions.
\end{abstract}

Keywords: Enzyme specificity, Catalytic promiscuity, Enzymes in organic synthesis, Enantioselectivity, Green chemistry

"I suspect they put Socrates to death because there is something terribly unattractive, alienating and nonhuman in thinking with too much clarity."-

The Bed of Procrustes by Nassim Nicholas Taleb

\section{Introduction}

The basic tenet of white biotechnology is to minimize damage to the environment rather than taking recourse to remediation as an "end of the pipe" solution [1,2]. Enzymes either in isolated form or in the form of whole cells can play an important role because of their two well known virtues. The biocatalysts normally do not require high temperature or other conditions which involve high consumption of energy. The biocatalysts are believed to be fairly specific, which would mean less number of side reactions. Side reactions lead to side products which lower the atom economy of the reactions. These side reactions hence lower the yield of the desired product (making the catalysis less efficient) and necessitate complicated downstream processing.

This review discusses the paradigm shifts over the years in our understanding of the enzyme specificity. It also explains why so called lack of specificity is also a good news as far as the usefulness of enzymes in biotechnology

\footnotetext{
* Correspondence: munishwar48@yahoo.co.uk

${ }^{2}$ Department of Biochemical Engineering and Biotechnology, Indian Institute of Technology Delhi, Hauz Khas, New Delhi 110016, India

Full list of author information is available at the end of the article
}

is concerned. The most dramatic departure from the classical concept of enzyme specificity is seen in the phenomenon of catalytic promiscuity. This refers to the same enzyme catalyzing very different kinds of biotransformations [3-6].

\section{Classification of enzymes and enzyme specificity}

Most of the people have forgotten (understandable since it disappeared from the standard texts many decades back!) that initially proteins were classified according to their solubility in various solvents. The five classes of proteins were albumins (soluble in water and salt solutions), globulins (sparingly soluble in water but soluble in salt solutions), prolamines (soluble in 70-80\% ethanol), glutenins (soluble in acid or alkali) and scleroproteins (insoluble in aqueous solvents) [7]. As our knowledge of proteins grew, the distinction between these various classes became fluid and in fact confusing. The enzymes, in the early phase of biochemistry became the most important and most studied class of proteins. These were named in a random fashion just as people name buildings, streets and monuments. Many of these names persist e.g. catalase, trypsin, lysozyme etc. Many of these names were based upon the nature of their catalytic activity. Lysozyme is named so as it lyses cells. So, the nomenclature and catalytic specificity have a long history in the area of biocatalysis.

The idea of a particular structure being absolutely related to a biological activity has been considered the hallmark of biology for many decades. Hence, it is not surprising that enzyme commission classification was based upon the type 
of reaction the enzyme catalyzes -hydrolysis, isomerisation or redox reactions etc. [8]. This in retrospect may not have been such a wise move as we believed till now.

In 1955-56, International Commission of enzymes was set up and that is how the EC classification came into being [8]. As we know, this classification provides a number with four figures. It is worth noting that all the four figures relate to the details of the specificity of the enzyme. The firm belief was that if one is able to pin down complete details of the specificity, one has described the enzyme and that is its identity.

\section{Various kinds of enzyme promiscuity}

Nothing promotes a scientific direction asmuch as coining a new term. System biology, nanotechnology and synthetic biology are illustrative examples. Enzyme promiscuity is also a case in point. As Hult and Burglund [9] pointed out, promiscuous catalysis by pyruvate decarboxylase of formation of C-C bonds was reported in 1921 and forms the basis of a current industrial process. Khersonsky and Tawfik [4] have also cited examples of few other well known enzymes which, many decades back, were reported to catalyse reactions "in addition to the ones for which they are physiologically specialized or evolve...". As Babtie et al. [10] highlighted "Promiscuous activities are generally considerably less efficient than the primary function of an enzyme, but second order rate constants $\left(\mathrm{k}_{\mathrm{cat}} / \mathrm{K}_{\mathrm{M}}\right)$ as high as $10^{5} \mathrm{M}^{-1} \mathrm{~s}^{-1}$ and rate accelerations $\left(\left(\mathrm{k}_{\mathrm{cat}} / \mathrm{K}_{\mathrm{M}}\right) / \mathrm{k}_{2}\right)$ up to $10^{18}$ have been reported: these values match or exceed those for many native enzymatic reactions.". After initial loose usages of the terms (associated with promiscuous behaviour of enzymes), there is clarity that broad specificity of an enzyme in terms of catalysis of the same reaction with range of substrates should be called substrate promiscuity. Instances when an enzyme catalyses a different reaction (which is not believed to be physiologically relevant at that point in evolution) with a different transition state should be termed as examples of catalytic promiscuity $[9,10]$.

Hult and Berglund [9] go a step further and suggest that reverse reactions catalysed by enzymes in many nonaqueous media or co-solvents can be classified as condition promiscuity. In such cases, the transition state may be same as in normal reactions. So, this may be little confusing.

Enzyme promiscuity started as being perceived as "associated with unwanted side effects, poor catalytic properties and errors in biological function" [11]. Today, it is increasingly being perceived as immensely useful phenomenon which can dramatically enhance utility of biocatalysis in biotechnology.

Babtie et al. [10] have provided a good discussion on how catalytic promiscuity may operate. Apart from the different amino acids of the active site involved in a qualitative or quantitative fashion during binding of the "alternative substrates", hydrophobic interactions may have an important role to play. Not only during binding, even during catalytic steps, the contributions of the active site residues may differ qualitatively and/or quantitatively. This "accidental promiscuity" observed in wild forms of the enzymes should be distinguished from "induced promiscuity" exhibited by mutants obtained by protein engineering or directed evolution [12]. Many excellent reviews (other than those already quoted above) which include evolutionary aspects of promiscuity are available $[3,13,14]$.

\section{Condition promiscuity of enzymes}

Hydrolases hydrolyse substrates. What happens if water is nearly absent? Advent of non-aqueous enzymology showed that exploring this possibility led to carrying out biocatalysis in nearly anhydrous organic solvents $[15,16]$, reverse micelles [17,18], ionic liquids [19-22] etc. So, a lipase in low water containing organic solvent synthesizes an ester bond and is obviously not functioning as a hydrolase [23].

This has been a very useful discovery. It has been also very important as it opened up huge possibilities of using enzymes in biotransformations [16,24] [Figure 1]. Not only it makes it possible to use inexpensive hydrolases like proteases and lipases in organic synthesis, it provides an additional handle of medium engineering $[25,26]$. Changing the organic solvent may change the enantioselectivity $[27,28]$. The other possibilities emerged e.g. using organic solvents as co-solvents [29] or using biphasic systems consisting of aqueous medium and water immiscible organic solvents [30]. One can use organic solvent phase to dissolve substrates and aqueous phase can contain the enzyme. This makes the catalytic process very efficient in case the substrate inhibition is involved [31]. If the product also goes back to the organic phase, shifting of the equilibrium (in favour of product formation) and overcoming product inhibition (if involved) are both achieved. More new possibilities continue to emerge. As Dordick's group showed few years back, nanotube mediated assembly of enzymes at the interface of aqueous and organic media overcomes the transport limitations typical of such biphasic systems [32].

It incidentally also meant that one could use green solvents for biocatalysis such as glycerol, ethanol, succinate esters, lactate esters, limonene and supercritical fluids [34]. The case of glycerol is especially relevant in the context of white biotechnology as massive amounts of glycerol are generated during biodiesel production and hence fits in well with the biorefinery concept. The biodiesel as such can be obtained from wastes and can be a good example of waste valorization [35-37] [Figure 2]. Many of the above mentioned solvents also, in principle, can be obtained from non food biomass or waste food materials 


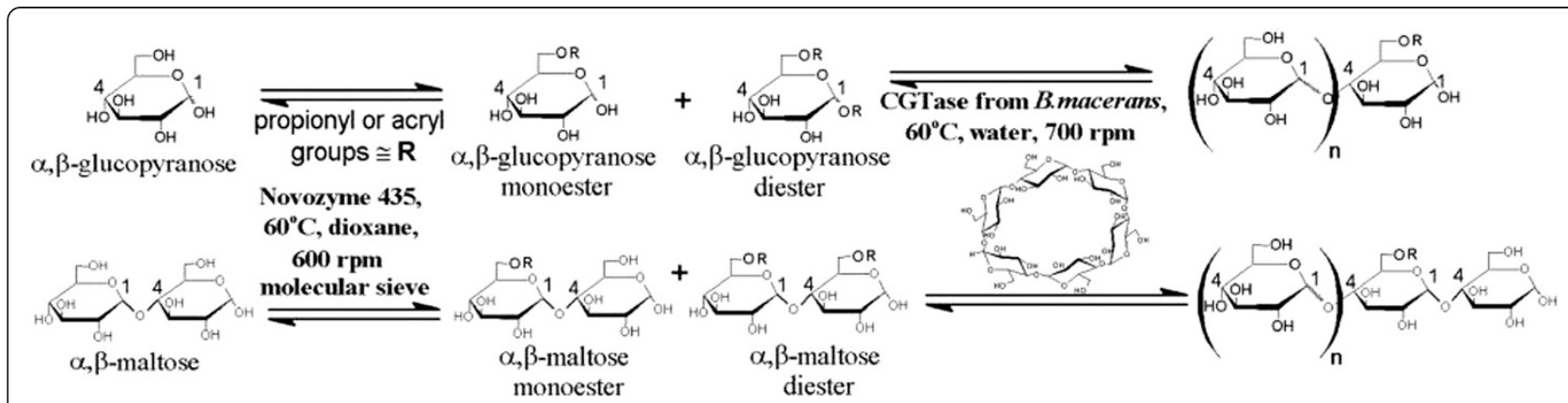

Figure 1 Lipase catalyzed transesterification of $\alpha, \beta$-glucose or $\alpha, \beta$-maltose with vinyl propionate or ethyl acrylate as acyl donor produced monoesters and diesters. $\mathbf{a}$-Cyclodextrin and the mentioned ester products, were substrates in the second reaction catalyzed by CGTase from B. macerans to produce oligosaccharide esters. [Reproduced from Ref [33] with permission from Chemistry Central].

[35]. All this points out to the emerging contours of a chemical industry based upon sustainable practices.

These possibilities have emerged as our classical concept of hydrolases will be always hydrolases turned out to be not absolutely valid. If you change the reaction condition, enzymes show condition promiscuity. That has not turned out to be bad at all from the perspective of white biotechnology.

\section{Catalytic promiscuity: recent results}

As many examples of catalytic promiscuity have been covered in quite a few recent reviews [5,38,39], we will mostly focus on literature pertaining to last couple of years. Rather than aiming at being comprehensive, the thrust of this review is on illustrating how catalytic promiscuity can be exploited to create novel possibilities in the area of biocatalysis driving the growth of white biotechnology. Some examples of reactions carried out using catalytic promiscuity for the synthesis of organic compounds in the authors' laboratory are illustrated in Table 1. Also, we have mostly limited ourselves to examples of accidental promiscuity rather than including ever growing number of examples where catalytic promiscuity has been tailored by using protein engineering or directed evolution.

\section{Catalytic promiscuity of lipases}

Single pot multicomponent reactions are an efficient synthetic strategy especially if accompanied by good atom

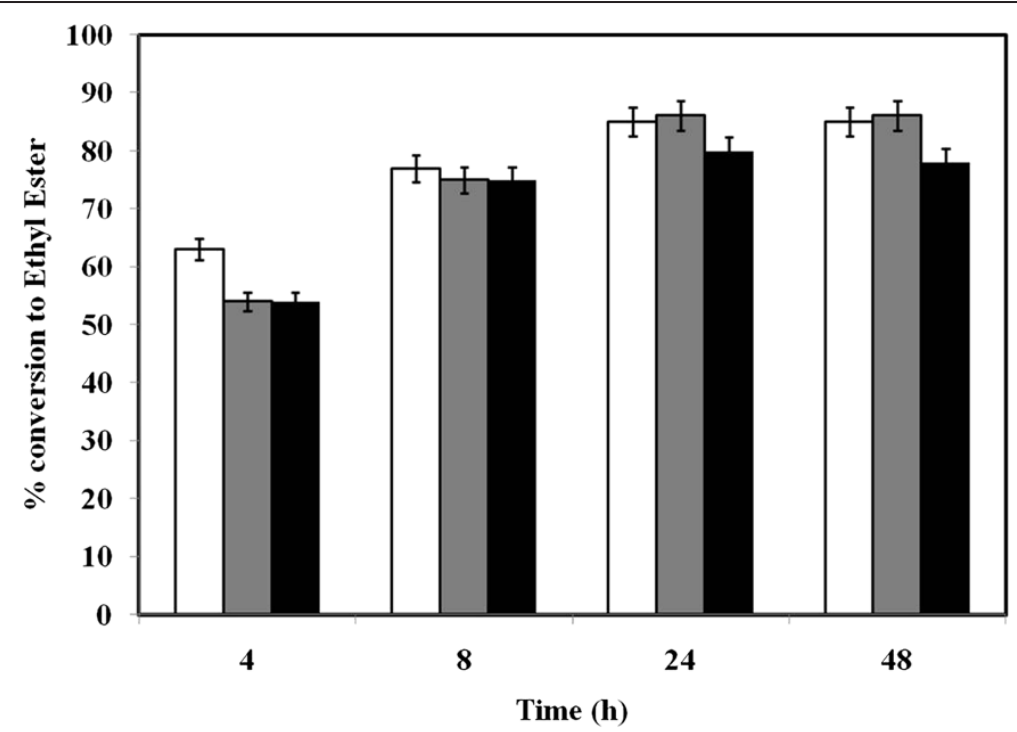

Figure 2 Biodiesel conversion with clean oil using Novozym 435 + RMIM. Reactions were performed taking $0.5 \mathrm{~g}$ coffee oil. Ethanol was added in molar ratio 4:1 (ethanol: oil). Novozym 435 + RMIM = 3:1 (White Bars); 37.5 mg of enzyme Novozym 435 (enzyme load being 7.5\% w/w of oil) and $12.5 \mathrm{mg}$ of enzyme RMIM (enzyme load being 2.5\% w/w of oil) was added. Novozym 435 + RMIM = 1:1 (Grey Bars); $25 \mathrm{mg}$ of enzyme Novozym 435 (enzyme load being 5\% w/w of oil) and 25 mg of enzyme RMIM (enzyme load being 5\% w/w of oil) was added. Novozym $435+$ RMIM = 1:3 (Black bars); 12.5 mg of enzyme Novozym 435 (enzyme load being 2.5\% w/w of oil) and 37.5 mg of enzyme RMIM (enzyme load being $7.5 \% \mathrm{w} / \mathrm{w}$ of oil) was added. [Reproduced from Ref [37] with permission from Chemistry Central]. 
Table 1 Some interesting examples of organic compounds synthesized in the authors' laboratory exploiting catalytic promiscuity

\begin{tabular}{|c|c|c|}
\hline Structure of the compound & Substrate and reaction conditions & Reference \\
\hline & Substrate: 5-Hydroxy-endo tricyclo [5.2.1.02,6] deca-4,8-dien-3-one and vinyl acetate & {$[40]$} \\
\hline & Biocatalyst: Novozyme 435 & \\
\hline & Solvent: Vinyl acetate (substrate) containing $10 \%$ (v/v) pyridine/DMF & \\
\hline
\end{tabular}<smiles>CC(=O)CC(O)c1ccc([N+](=O)[O-])cc1</smiles>

Substrate: $p$-nitrobenzaldehyde and ethyl acetoacetate

Biocatalyst: Lipases from Candida antarctica lipase B, Mucor javanicus, Mucor miehei, Candida rugosa and Novozyme 435

Solvent: Aqueous organic co-solvent mixtures were used as the solvent<smiles>CC(=O)C(=C(C)O)[C@@H](O[C@H](C(C)=O)C(C)=C(C)O)c1ccc([N+](=O)[O-])cc1</smiles>

Substrate: $p$-nitrobenzaldehyde and acetyl acetone

Biocatalyst: Lipases from Candida antarctica lipase B, Mucor javanicus, Mucor miehei, Burkholderia cepacia and Novozyme 435

Solvent: Aqueous organic co-solvent mixtures<smiles>CC(=O)C1=C(C)OC(C)=C(C(C)=O)C(c2ccc([N+](=O)[O-])cc2)OC1c1ccc([N+](=O)[O-])cc1</smiles><smiles>O=[N+]([O-])c1ccc(CO)cc1</smiles>

Substrate: $p$-nitrobenzaldehyde

Biocatalyst: Novozyme 435

Solvent: Aqueous buffer<smiles>O=C(O)c1ccc([N+](=O)[O-])cc1</smiles> 
economy. Zhang [44] showed that porcine pancreatic lipase (PPL) could be used to synthesize a number of 2, 4-disubstituted thiazoles with methanol as the organic solvent. Their interest in synthesis of these compounds was due to their many biological activities. There are several noteworthy features of this work. Use of organic solvents (as compared to water or aqueous-organic co-solvent mixtures) has been underexploited in the context of catalytic promiscuity of enzymes. More important, some amylase preparations have also been shown to be catalysing this reaction. It is very likely that enzymes used in this work were industrial grade preparations and may have been contaminated by lipase activities. Earlier, it took several decades before Nakajima's group could show that lipases (contrary to an earlier claim) if purified do not catalyse peptide synthesis in organic solvents [45]. As we explore more and more catalytic promiscuity of enzymes, it is necessary that we keep in mind that some of these may be caused by contaminating proteins. Another important point is that methanol as a solvent was far superior to ethanol. That is unfortunate as ethanol, unlike methanol, is a green solvent. So, from sustainability point of view, perhaps we need to separately screen out a panel of green solvents and determine which one is the best, even if not as good as another non green solvent.

Ugi reaction is one of the more well known multicomponent reactions [46]. The classic Ugi reaction involves condensation of a primary amine, a carbonyl compound, carboxylic acid and isocyanide. Kzossowski et al. [47] have shown that Novozym 435 could form a peptide bond in organic solvents like toluene and chloroform. An important objective of white biotechnology has been to be able to operate chemical processes starting with simple set of compounds [34] which can be obtained from renewable resources. In that respect, peptide bond formation starting with an amine, aldehyde and isocyanide (rather than two amino acids) is a good advancement and shows the wide ranging promise and potential of catalytic promiscuity.

\section{Catalytic promiscuity: beyond lipases}

The phenomenon of catalytic promiscuity has turned out to be far more widespread than initially believed. While earlier, there was a strong focus on the use of lipases for C-C bond formation reactions [38,40,41,48,49], use of other enzymes in catalyzing diverse kinds of reactions is being increasingly demonstrated. Liu et al. [50] have reported asymmetric aldol reactions between isatin derivatives with cyclic ketones catalyzed by nuclease $\mathrm{p} 1$ from Penicillium citrinum. This example of catalytic promiscuity provides a green approach for the synthesis of pharmaceutically active compounds. Li et al. [51] had earlier used the same enzyme for catalyzing asymmetric aldol reactions between aromatic aldehydes and cyclic ketones under solvent-free conditions. The catalytic promiscuity of Escherichia coli BioH esterase was recently exploited for the synthesis of 3, 4-dihydropyran derivatives [52]. The authors used a series of substituted benzalacetones and 1 , 3 -cyclic diketones as reactants in anhydrous DMF, with yields as high as $76 \%$ being obtained in some cases. Recently, ficin from fig tree latex (a plant cysteine proteinase) was shown to catalyze the direct asymmetric aldol reactions of nitrogen, oxygen or sulphur containing heterocyclic ketones with aromatic aldehydes in organic medium [53]. Earlier work from the same group showed that commercially available papain (from Carica papaya latex) can be used as an efficient catalyst for Knoevenagel reactions involving a wide range of substrates [54]. Zheng et al. [55] developed the trypsin catalyzed one-pot multicomponent synthesis of 4-thiazolidinones as a novel strategy for the synthesis of this important group of heterocyclic compounds. The derivatives of 2H-1-benzopyran-2-one form the scaffold of many pharmaceuticals $[56,57]$. Wang et al. [58] have used an alkaline protease from $B$. licheniformis to obtain these by domino Knoevanagel/intramolecular transesterification reactions in low water containing organic solvents.

An interesting example of exploiting catalytic promiscuity for carrying out domino, single-pot reactions was reported by Zhou et al. [59]. The authors used $\alpha$-amylase from Bacillus subtilis for catalyzing the oxa-Michael/aldol condensation for the synthesis of substituted chromene derivatives. Gao et al. [60] described Henry reactions catalyzed by glucoamylase from Aspergillus niger. The reactions carried out in mixed solvents of ethanol and water, formed the $\beta$-nitroalcohols in yields upto $99 \%$.

One emerging concern has been the bacteria developing resistance towards existing antibiotics like in the case of aminoglycosides which are broad spectrum antibiotics [61]. The catalytic promiscuity of aminoglycoside acetyl transesterases was utilized for chemoenzymatic synthesis of variety of novel molecules including acylated aminoglucosides which show promise in circumventing bacterial resistance towards existing antibiotics. The synthetic strategy avoids longer multistep processes. Werneburg et al. [62] have used the polyketide synthetase for preparative scale synthesis of 15 new aureothin (a shikimate-polyketide with antimicrobial and antitumor activities) analogs, many with less cytotoxicity but improved anti-proliferative action. It may be noted that engineered mutants of the organism were used. So, it is an example of metabolic engineering wherein the strategy was based upon the catalytic promiscuity of the enzyme.

Alcohol dehydrogenases (ADHs) are enzymes which catalyze the transformation of ketones/aldehydes to the corresponding alcohols and vice versa at the expense of a nicotinamide cofactor that acts as hydride donor and acceptor respectively [63]. Of the many approaches 
available for co-factor recycling, a simple way is to use a co-substrate such as propanol $[64,65]$. Gotor's group [66] has used ADHs from L. brevis, R.ruber and Thermoanaerobacter sp. to carry out regioselective and stereoselective reductions of 1,2-and 1,3- diketones to obtain enantiopure hydroxyketones or diols. Some cyclic diketones were also reduced. The co-substrate propanol was used for cofactor regeneration in this case as well. While the reaction carried out was essentially a normal one, the binding modes of the substrates were different with different ADHs and show how different parts of the active site of the enzymes can be involved in binding. This is a good illustration of substrate promiscuity being exploited for designing useful synthetic strategies. An interesting example of catalytic chemo-promiscuity of alcohol dehydrogenase was reported by Ferreira-Silve et al. [67]. The authors observed that some alcohol dehydrogenases transformed phenylacetaldoxime to the primary alcohol via the imine and aldehyde intermediates, suggesting that the hydride of the co-factor was transferred to the $\mathrm{N}$-atom of the oxime moiety rather than the $\mathrm{C}$-atom.

Alanine racemase is a key PLP-dependant enzyme in cyclosporine (a well known immunosuppressant drug) biosynthesis. Di Salvo et al. [68] reported that just like serine hydroxymethyl transferase and threonine aldolase, the cloned racemase was able to carry out both retroaldol cleavage and transamination reactions. It is a strong evidence that these three enzymes illustrate divergent evolution from a common ancestor which perhaps singly performed all these individual reactions. So, the specialised functions evolved but the enzymes retained features which are responsible for the promiscuous behaviour.

A novel protocol for the D-aminoacylase catalyzed double Michael addition was developed by Chen et al. [69]. The reactions, which were used for the synthesis of (hetero)spiro[5.5] undecane derivatives produced the cis isomers in all the cases. Grulich et al. [70] provide a useful summary of the applications of Penicillin G acylases which are known to catalyse transesterifications, Markonikov additions or Henry reactions. Unfortunately, the catalytic efficiency reported so far in these promiscuous reactions is far from satisfactory for any biotechnological applications. However, as Nobeli et al. [11] had pointed out, such results lay the foundation of subsequent efforts using protein engineering/ directed evolution to improve upon these catalytic activities. Large number of successful results which prove this are already available in the literature [12,71-73].

He et al. [74] reported for the first time that hen egg white lysozyme (HEWL) efficiently promotes the onepot, three-component aza-Diels-Alder reaction of aromatic aldehydes, aromatic amine and 2-cyclohexen-1-one. Under optimised conditions, yields up to $98 \%$ and stereoselectivity of endo/exo ratios up to 90:10 were obtained.
Similarly, Baas et al. [75] have reviewed the enzyme promiscuity in five members of the tautomerase super family. These enzymes show diverse catalytic activities encompassing $\mathrm{C}-\mathrm{H}, \mathrm{C}-\mathrm{C}, \mathrm{C}-\mathrm{O}$ and carbon-halogen bonds. The review of Baas et al. [75] discusses how looking at promiscuous activities helps in understanding of mechanism of normal activities of the enzymes. It is interesting that all enzymes have $\mathrm{N}$-terminal proline as a key catalytic residue. It is very well established that some amino acids as such catalyse diverse kinds of reactions on their own $[76,77]$.Obviously, the catalytic promiscuity of enzymes has its origin in confluence of different factors [11]. Table 2 summarizes the usefulness of catalytic promiscuity in biocatalysis (Table 2).

Archae constitute the oldest organisms on our earth. Given the harsher conditions prevalent in those days, archae are prominent examples of extremophiles. The specialised functions of the enzymes (part of the evolved metabolism) in more complex organism have evolved from the small number of enzymes which these ancestors had. So, these organisms constitute valuable systems to track extensive promiscuity shown by the early enzymes. Jia et al. have detailed both promiscuity as well as moonlighting shown by archae enzymes [82]. Archae enzymes are rich in intrinsic disorder. Jia et al. [82] point out that capacity for the structure to survive under harsh conditions and multitasking (which is seen as promiscuity and moonlighting) required conformational pliability. It is interesting that many "hub proteins" important in metabolic regulations in many organisms have been found to be intrinsically disordered proteins (IDPs) [83]. So, promiscuity is one facet of the evolutionary design of enzymes. As Skolnick et al. [84] state, promiscuous behaviour is the biochemical noise (low level, ligand-protein interactions) which was nearly impossible to eliminate as enzyme molecules evolved to assume specialised catalytic roles.

The example of glutathione transferase is especially interesting. Atkins group [85] have discussed that two isoforms of glutathione transfereases in humans vastly differ in their catalytic promiscuity. This highlights the conceptual relationship between the phenomenon of isoenzymes to promiscuous behaviour as pointed out by one of us few years back [5]. The A-class GSTA1-1 showed the fairly wide substrate specificity as a detoxification enzyme. On the other hand, GSTA4-4 acted upon lipid peroxidation products. This was one of the early reports to point out that "conformational plasticity" is inbuilt to achieve catalytic promiscuity at the cost of stability [85]. More recent work from the same group [86] concludes that smooth barrier free transitions within the local conformational landscape of the active site is associated with the more promiscuous GST. Furthermore, local molten globule behaviour optimizes the catalytic function of the GST in detoxification [87]. So, catalytic promiscuity may not be 
Table 2 Applications of catalytic promiscuity for useful biotransformations

\begin{tabular}{|c|c|c|c|}
\hline Biotransformations & Substrate (s) & Enzyme (s) & References \\
\hline $\begin{array}{l}\text { Regio- and stereoselective } \\
\text { reductions }\end{array}$ & Diketones & $\begin{array}{l}\text { ADHs from Lactobacillus kefir, Rhodococcus } \\
\text { ruber, Thermoanaerobacter etc. }\end{array}$ & [66] \\
\hline Reduction reaction & Phenylacetaldoxime & $\begin{array}{c}\text { ADHs from Rhodococcus ruber, Ralstonia sp., } \\
\text { Thermoanaerobacter etc. }\end{array}$ & [67] \\
\hline Aza-Diels-Alder reaction & 4-chlorobenzaldehyde, cyclohexenone, 4-anisidine & Hen egg white lysozyme (HEWL) & [74] \\
\hline $\begin{array}{l}\text { Domino Knoevenagel/ } \\
\text { intramolecular transesterification }\end{array}$ & Salicylaldehyde, ethyl acetoacetate & $\begin{array}{l}\text { Alkaline protease from Bacillus } \\
\text { licheniformis (BLAP) }\end{array}$ & [58] \\
\hline Transesterification reaction & Guaifenesin, vinyl acetate & Penicillin $\mathrm{G}$ acylase & [78] \\
\hline Knoevenagel reaction & Aromatic aldehyde, acetyl acetone/Ethyl acetoacetate & Papain from Carica papaya latex & [54] \\
\hline $\begin{array}{l}\text { Ugi reaction for peptide } \\
\text { synthesis (MCR) }\end{array}$ & Aldehyde, amine, isocyanide & $\begin{array}{l}\text { Novozyme } 435 \text { (commercially available, } \\
\text { immobilized Candida antarctica lipase B) }\end{array}$ & [47] \\
\hline Asymmetric aldol reaction & Aromatic aldehyde, cyclic ketone & Nuclease p1 from Penicillium citrinum & [51] \\
\hline Asymmetric aldol reaction & Heterocyclic ketone, aromatic aldehyde & Ficin from fig tree latex & [53] \\
\hline Synthesis of 4-thiazolidinones & Aromatic aldehyde, benzyl amine, mercaptoacetic acid & Trypsin from porcine pancreas & [55] \\
\hline $\begin{array}{l}\text { Domino oxa-Michael/aldol } \\
\text { condensations }\end{array}$ & Salicylaldehyde, methyl vinyl ketone & a-amylase from Bacillus subtilis & [59] \\
\hline Henry reaction & 4-cyanobenzaldehyde, nitromethane & Glucoamylase from Aspergillus niger (AnGA) & [60] \\
\hline $\begin{array}{l}\text { Retro aldol and transamination } \\
\text { reactions }\end{array}$ & $\begin{array}{l}\mathrm{L} \text {-threonine and } \mathrm{L} \text {-allo-threonine (for retro aldol } \\
\text { reaction); } \mathrm{D} \text { - and } \mathrm{L} \text {-alanine(for transamination reaction) }\end{array}$ & $\begin{array}{c}\text { Alanine racemase from Tolypocladium } \\
\text { inflatum }\end{array}$ & [68] \\
\hline Double Michael addition reaction & $\begin{array}{l}\text { Cyclohexane-1,3-dione and (1E,4E)-1, } \\
\text { 5-diphenylpenta-1,4-dien-3-one }\end{array}$ & D-amino acylase & [69] \\
\hline Enantioselective aldol reaction & Isatin derivatives, cyclic ketones & Nuclease p1 from Penicillium citrinum & [50] \\
\hline $\begin{array}{l}\text { Synthesis of 2,4-disubstituted } \\
\text { thiazoles (MCR) }\end{array}$ & $\begin{array}{l}\text { Benzylamine, isobutyraldehyde, thioacetic acid, } \\
\text { methyl 3-(dimethylamino)-2-isocyanoacrylate }\end{array}$ & Porcine pancreatic lipase (PPL) & [44] \\
\hline $\begin{array}{l}\text { Michael addition-cyclization cas- } \\
\text { cade reaction }\end{array}$ & Substituted benzalacetones and 1,3-cyclic diketones & E.coli BioH esterase & [52] \\
\hline $\begin{array}{l}\text { Synthesis of substituted } \\
2 \mathrm{H} \text {-chromemes (MCR) }\end{array}$ & Salicylaldehyde, acetophenone, methanol & Porcine pancreatic lipase & [79] \\
\hline Baylis-Hillman reaction & p-nitrobenzaldehyde and methyl vinyl ketone & E.coli BioH esterase & {$[80]$} \\
\hline Biginelli reaction $(\mathrm{MCR})^{*}$ & Urea, ethyl acetoacetate, vinyl acetate & Trypsin from porcine pancreas & [81] \\
\hline
\end{tabular}

*stands for Multi-component reaction.

just accidental "noise" [84] but part of an intentional biocatalytic design.

Labrou's group [88] have recently reported a GST from A. tumefaciens which represents a novel class of bacterial GST superfamily. Its active site is quite different from cytosolic GST reported so far. It may be interesting to see the unravelling of its specificity in the years to come. Finally, as pointed out by them, GSTs are also possibly involved in the storage and transportation of wide variety of biological molecules and thus are also moonlighting proteins. This three way correlation between isoenzymes, promiscuous enzymes and moonlighting proteins have been pointed out earlier [5]. To sum up, the conformational pliability may be local or global in protein structure as the cause behind promiscuity.

\section{Conclusions}

Few trends are clear. While during early few years, examples of catalytic promiscuity were mostly concerned with applications of lipases; last few years have seen other classes of enzymes (other hydrolases, oxidoreductases, transferases etc.) being equally capable of showing catalytic promiscuity.

The shift from our belief in enzyme specificity to the realization that these biocatalysts are fairly promiscuous has not been gradual. Some key milestones can be identified. We accepted the idea of broad specificity (lately called relaxed specificity) long ago. Isoforms or isoenzymes, the enzymes from the same organism, carrying similar catalytic activity but with different specificity and kinetic behaviour have been again known since several decades [5]. The catalysis starts with molecular recognition of the "substrate" by the enzyme. The binding site, part of the active centre was known to show promiscuous behaviour when textile dyes emerged as powerful affinity ligands [89]. The catalytic promiscuity largely arises because many different "substrates" can interact with different side chains of amino acids to result in different transition states. 
This is akin to a general practitioner becoming a specialist in medical science but retaining enough knowledge of how to treat many diseases. In the beginning, we had RNA world [90]. Then came early enzymes. As complex metabolisms were required with evolution of more complex organisms, more specialised enzymes emerged. These enzymes did not forget entirely what their ancestors were capable of.

White biotechnology can definitely profit by exploiting many of the catalytic powers which enzymes did not entirely "forget"! This overview has looked at the proverbial "tip of the iceberg". Hopefully, it will draw attention of many biotechnologists to look at the huge iceberg of potential application of these green catalysts to nurture sustainable approaches in chemical industries.

\section{Competing interests}

The authors declare that they have no competing interests.

\section{Authors' contributions}

BA played a large role in the search for the current literature. All authors participated in drafting of the text, read and approved the final manuscript.

\section{Acknowledgements}

We thank Prof. Prashant Mishra for his interest in this work and several related discussions. We acknowledge financial support from the Government of India's Department of Science and Technology (DST) [Grant No.: SR/SO/ BB-68/2010]. BA and JM thank the Council of Scientific and Industrial Research for the Senior Research Fellowship.

\section{Author details}

${ }^{1}$ Department of Chemistry, Indian Institute of Technology, Delhi, Hauz Khas, New Delhi 110016, India. ${ }^{2}$ Department of Biochemical Engineering and Biotechnology, Indian Institute of Technology Delhi, Hauz Khas, New Delhi 110016, India.

Received: 27 August 2014 Accepted: 10 December 2014

Published online: 31 December 2014

\section{References}

1. Gupta MN, Raghava S: Relevance of chemistry to white biotechnology. Chem Cent J 2007, 1:17.

2. Ulber R, Sell D: White Biotechnology. Berlin: Springer-Verlag; 2007.

3. Kazlauskas RJ: Enhancing catalytic promiscuity for biocatalysis. Curr Opin Chem Biol 2005, 9:195-201.

4. Khersonsky O, Tawfik DS: Enzyme promiscuity: a mechanistic and evolutionary perspective. Annu Rev Biochem 2010, 79:471-505.

5. Gupta MN, Kapoor M, Majumder AB, Singh V: Isozymes, moonlighting proteins and promiscous enzymes. Curr Sci 2011, 100:1152-1162.

6. Gupta MN, Mukherjee J: Enzymology: some paradigm shifts over the years. Curr Sci 2013, 104:1178-1186.

7. Fruton JS, Simmons S: General Biochemistry. New York: Wiley and Sons Inc; 1958.

8. Dixon M, Webb EC: Enzymes. London: Academic Press; 1964.

9. Hult K, Berglund P: Enzyme promiscuity: mechanism and applications. Trends Biotechnol 2007, 25:231-238.

10. Babtie A, Tokuriki N, Hollfelder F: What makes an enzyme promiscuous. Curr Opin Chem Biol 2010, 14:1-8.

11. Nobeli I, Favia AD, Thornton JM: Protein promiscuity and its implications for biotechnology. Nat Biotechnol 2009, 27:157-167.

12. Goldsmith M, Tawfik DS: Directed enzyme evolution: beyond the low-hanging fruit. Curr Opin Struc Biol 2012, 22:406-412.

13. O'Brien PJ, Herschlag D: Catalytic promiscuity and the evolution of new enzymatic activities. Chem Biol 1999, 6:R91-R105.

14. Humble MS, Berglund P: Biocatalytic promiscuity. Eur J Org Chem 2011, 2011:3391-3401
15. Gupta MN: Enzyme function in organic solvents. Eur J Biochem 1992, 203:25-31.

16. Vulfson EN, Halling PJ, Holland HL: Enzymes in Nonaqueous Solvents: Methods and Protocol. New Jersey: Humana Press; 2001

17. Martinek K, Levashov AV, Klyachko N, Khmelnitsky YL, Berezin IV: Micellar enzymology. Eur J Biochem 1986, 155:453-468.

18. Martinek K, Berezin IV, Khmelnitsky YL, Klyachko NL, Levashov AV: Enzymes entrapped into reversed micelles of surfactants in organic solvents: key trends in applied enzymology (Biotechnology). Biocatal Biotransform 1987, 1:9-15.

19. Park S, Kazalauskas RJ: Improved preparation and use of room temperature ionic liquids in lipase-catalyzed enantio- and regioselective acylations. J Org Chem 2001, 66:8395-8401.

20. Park S, Kazalauskas RJ: Biocatalysis in ionic liquids - advantages beyond green technology. Curr Opin Biotechnol 2003, 14:432-437.

21. Shah S, Gupta MN: Kinetic resolution of ( \pm )-1-phenylethanol in [Bmim] $\left[\mathrm{PF}_{6}\right]$ using high activity preparations of lipases. Bioorg Med Chem Lett 2007, 17:921-924.

22. Zhao $\mathrm{H}$ : Methods for stabilizing and activating enzymes in ionic liquids-a review. J Chem Technol Biotechnol 2010, 85:891-907.

23. Kumari V, Shah S, Gupta MN: Preparation of biodiesel by lipase-catalyzed transesterification of high free fatty acid containing oil from madhuca indica. Energy Fuels 2007, 21:368-372.

24. Gupta MN: Methods in non-Aqueous Enzymology. Basel: Birkhauser Verlag; 2000.

25. Laane C: Medium engineering for bioorganic synthesis. Biocatalysis 1987, 30:80-87.

26. Gupta MN, Roy I: Enzymes in organic media: forms, function and applications. Eur J Biochem 2004, 271:2575-2583.

27. Wu SH, Chu FY, Wang KT: Reversible enantioselectivity of enzymatic reactions by media. Bioorg Med Chem Lett 1991, 1:339-342.

28. Tsai S, Huang CM: Enantioselective synthesis of (S)-ibuprofen ester prodrugs by lipases in cyclohexane. Enzyme Microb Technol 1999, 25:682-688.

29. Khmelnitsky YL, Mozhaev W, Belova AB, Sergeeva MV, Martinek K: Denaturation capacity: a new quantitative criterion for selection of organic solvents as reaction media in biocatalysis. Eur J Biochem 1991, 198:31-41.

30. Mattiasson B, Holst O: Extractive Bioconversions. New York: Marcel Dekker Inc; 1991.

31. Purich DL: Enzyme Kinetics: Catalysis \& Control. London: Academic Press; 2010.

32. Asuri P, Karajanagi S, Dordick JS, Kane R: Directed assembly of carbon nanotubes at liquid-liquid interfaces: nanoscale conveyors for interfacial biocatalysis. J Am Chem Soc 2006, 128:1046-1047.

33. Ayres BT, Valenca GP, Franco TT: Two-step process for preparation of oligosaccharide propionates and acrylates using lipase and Cyclodextrin Glycosyl Transferase (CGTase). Sus Chem Processes 2014, 2:6.

34. Boodhoo K, Harvey A: Process Intensification for Green Chemistry. London: Wiley and Sons Ltd; 2013.

35. Luque R, Clark JH: Valorisation of food residues: waste to wealth using green chemical technologies. Sus Chem Processes 2013, 1:10.

36. Pleissner D, Lin CS: Valorisation of food waste in biotechnological processes. Sus Chem Processes 2013, 1:21.

37. Banerjee A, Singh V, Solanki K, Mukherjee J, Gupta MN: Combi-protein coated microcrystals of lipases for production of biodiesel from oil from spent coffee grounds. Sust Chem Processes 2013, 1:14.

38. Busto E, Gotor-Fernandez V, Gotor V: Hydrolases: catalytically promiscuous enzymes for non-conventional reactions in organic synthesis. Chem Soc Rev 2010, 39:4504-23.

39. Kapoor M, Gupta MN: Lipase promiscuity and its biochemical applications. Process Biochem 2012, 47:555-569.

40. Majumder AB, Ramesh NG, Gupta MN: Lipase catalyzed condensation reaction with a tricyclic diketone-yet another example of biocatalytic promiscuity. Tetrahedron Lett 2009, 50:5190-5193.

41. Kapoor M, Majumder AB, Mukherjee J, Gupta MN: Decarboxylative aldol reaction catalysed by lipases and a protease in organic co-solvent mixtures and nearly anhydrous organic solvent media. Biocatal Biotransform 2012, 30:399-408.

42. Majumder $A B$, Gupta MN: Lipase-catalyzed condensationreaction of 4-nitrobenzaldehyde with acetyl acetone in aqueous-organic cosolvent mixtures and in nearly anhydrous media. Synth Commun 2014, 44:818-826

43. Arora B, Pandey PS, Gupta MN: Lipase catalyzed Cannizzaro-type reaction with substituted benzaldehydes in water. Tetrahedron Lett 2014, 55:3920-3922. 
44. Zhang $\mathrm{H}$ : A novel one-pot multicomponent enzymatic synthesis of 2,4-disubstituted thiazoles. Catal Lett 2014, 144:928-934.

45. Maruyama T, Nakajima M, Kondo H, Kawasaki K, Seki M, Goto M: Can lipases hydrolyse a peptide bonds? Enzym Microb Technol 2003, 32:655-657.

46. Domling A, Ugi I: Multicomponent reactions with isocyanides. Angew Chem Int Ed 2000, 39:3168-3210.

47. Kzossowski S, Wiraszka B, Berzozecki S, Ostaszewski R: Model studies on the first enzyme-catalyzed Ugi reaction. Org Lett 2013, 15:566-569.

48. Branneby C, Carlqvist P, Magnusson A, Hult K, Brinck T, Berglund P. Carbon-carbon bonds by hydrolytic enzymes. J Am Chem Soc 2003, 125:874-875

49. Li C, Feng X-W, Wang N, Zhou Y-J, Yu X-Q: Biocatalytic promiscuity: the first lipase catalysed asymmetric aldol reaction. Green Chem 2008, 10:616-618.

50. Liu ZQ, Xiang ZW, Shen Z, Wu Q, Lin XF: Enzymatic enantioselective aldo reactions of isatin derivatives with cyclic ketones under solvent free conditions. Biochimie 2014, 101:156-160.

51. Li HH, He YH, Yuan Y, Guan Z: Nuclease p1: a new biocatalyst for direct asymmetric aldol reaction under solvent-free conditions. Green Chem 2011, 13:185-189.

52. Jiang L, Wang B, Li R, Shen S, Yu H, Ye L: Catalytic promiscuity of Escherichia coli BioH esterase: application in the synthesis of 3,4-dihydropyran derivatives. Process Biochem 2014, 49:1135-1138.

53. Fu JP, Gao N, Yang Y, Guan Z, He YH: Ficin-catalyzed asymmetric aldol reactions of heterocyclic ketones with aldehydes. J Mol Catal B Enzym 2013, 97:1-4.

54. Hu W, Guan Z, Deng X, He YH: Enzyme catalytic promiscuity: the papain-catalyzed Knoevenagel reaction. Biochemie 2012, 94:656-661.

55. Zheng H, Mei YJ, Du K, She QI, Zhang PF: Trypsin catalysed one-pot multicomponent synthesis of 4-thiazolidinones. Catal Lett 2013, 143:298-301

56. Chun K, Park SK, Kim HM, Choi Y, Kim MH, Park CH, Joe BY, Chun PG, Choi HM, Lee HY, Hong SH, Kim MS, Nam KY, Han G: Chromen-based TNF-a-converting enzyme (TACE) inhibitors: design, synthesis and biological evaluation. Bioorg Med Chem Lett 2008, 16:530-535.

57. Khode S, Maddi V, Aragade P, Palkar M, Ronad PK, Mamledesai S, Thippeswamy AHM, Satyanarayana D: Synthesis and pharmacological evaluation of a novel series of 5-(substituted)-aryl-3-(3-coumarinyl)-1phenyl-2-pyrazolines as novel anti-inflammatory and analgesic agents. Eur J Med Chem 2009, 44:1682-1688.

58. Wang $\mathrm{CH}$, Guan Z, He YH: Biocatalytic domino reaction: synthesis of 2H-1-benzopyran-2-one derivatives using alkaline protease from Bacillus licheniformis. Green Chem 2011, 13:2048-2054.

59. Zhou LH, Wang N, Zhang W, Xie ZB, Yu XQ: Catalytical promiscuity of a- amylase: synthesis of 3 -substituted $2 \mathrm{H}$-chromene derivatives via biocatalytic domino oxa-Michael/aldol condensations. J Mol Catal B Enzym 2013, 91:37-43.

60. Gao N, Chen YL, He YH, Guan Z: Highly efficient and large-scalable glucoamylase catalyzed Henry reactions. RSC Adv 2013, 3:16850-16856.

61. Green KD, Chen W, Houghton JL, Fridman M, Garneau-Tsodikova S: Exploring the substrate promiscuity of drug modifying enzymes for the chemoenzymatic generation of $\mathrm{N}$-acylated amino glycosides. ChemBioChem 2010, 11:119-126.

62. Werneburg M, Busch B, He J, Richter MEA, Xiang L, Moore BS, Roth M, Dahse HM, Hertweck C: Exploiting enzymatic promiscuity to engineer a focussed library of highly selective antifungal and anti proliferative aureothin analogs. J Am Chem Soc 2010, 132:10407-10413.

63. Kula MR, Kragl U: Dehydrogenases in the synthesis of chiral compounds. In Stereoselective Biocatalysis. Edited by Patel RN. New York: Marcel Dekker Inc; 2000:839-866.

64. Van der Donk WA, Zhao H: Recent developments in pyridine nucleotide regeneration. Curr Opin Biotechnol 2003, 14:421-426.

65. Kroutil W, Mang H, Edegger K, Faber K: Recent advances in the biocatalytic reduction of ketones and oxidation of sec-alcohols. Curr Opin Chem Biol 2004, 8:120-126.

66. Kurina-Sanz M, Bisogno FR, Lavandera I, Orden AA, Gotor V: Promiscuous substrate binding explains the enzymatic stereo and regiocontrolled synthesis of enantiopure hydroxyl ketones and diols. Adv Synth Catal 2009, 351:1842-1848.

67. Ferreira-Silve B, Lavandra I, Kern A, Faber K, Kroutil W: Chemo-promiscuity of alcohol dehydrogenases: reduction of phenylacetaldoxime to the alcohol. Terahedron 2010, 66:3410-3414.
68. di Salvo ML, Florio R, Paiardini A, Vivoli M, D'Aguanno M, Contestabile R: Alanine racemase from Tolypocladium inflatum: a key PLP-dependent enzyme in cyclosporine biosynthesis and a model of catalytic promiscuity. Arch Biochem Biophys 2013, 529:55-65.

69. Chen XY, Liang YR, Xu FL, Wu Q, Lin XF: Stereoselective synthesis of spiro [5.5] undecane derivatives via biocatalytic [5+1] double Michael additions. J Mol Catal B Enzym 2013, 97:18-22.

70. Grulich M, Stepanek V, Kyslik P: Perspectives and industrial potential of PGA selectivity and promiscuity. Biotechnol Adv 2013, 31:1458-1472.

71. Soskine M, Tawfik DS: Mutational effects and the evolution of new protein functions. Nature Rev Genet 2010, 11:572-582.

72. Meier MM, Rajendran C, Malisi C, Fox NG, Xu C, Schlee S, Barondeau DP, Hocker B, Sterner R, Raushel FM: Molecular engineering of organophosphate hydrolysis activity from a weak promiscuous lactonase template. J Am Chem Soc 2013, 135:11670-11677.

73. Jung S, Kim J, Park S: Rational design for enhancing promiscuous activity of Candida antarctica lipase B: a clue for the molecular basis of dissimilar activities between lipase and serine-protease. RSC Adv 2013, 3:2590-2594.

74. He YH, Hu W, Guan Z: Enzyme catalysed direct three component Aza Diels Alder reaction using hen egg white lysozyme. J Org Chem 2012, 77:200-207.

75. Baas BJ, Zandvoort E, Geertsema EM, Poelarends GJ: Recent advances in the study of enzyme promiscuity in the tautomerase super family. ChemBioChem 2013, 14:917-926.

76. Jarvo ER, Miller SJ: Amino acids and peptides as asymmetric organocatalysts. Tetrahedron 2002, 58:2481-2495.

77. Notz W, Tanaka F, Barbas CF III: Enamine-based organocatalysis with proline and diamines: the development of direct catalytic asymmetric aldol, Mannich, Michael and Diels-Alder reactions. Acc Chem Res 2004, 37:580-591.

78. Liu $B, W u Q, L v D$, Lin X: Modulating the synthetase activity of penicillin $G$ acylase in organic media by addition of $\mathrm{N}$-methylimidazole: using vinyl acetate as activated acyl donor. J Biotechnol 2011, 153:111-115.

79. Yang F, Wang Z, Wang H, Zhang H, Yue H, Wang L: Enzyme catalytic promiscuity: lipase catalyzed synthesis of substituted $2 \mathrm{H}$-chromenes by a three-component reaction. RSC Adv 2014, 4:25633-25636.

80. Jiang L, Yu HW: An example of enzymatic promiscuity: the Baylis-Hillman reaction catalyzed by a biotin esterase $(\mathrm{BioH})$ from Escherichia coli. Biotechnol Lett 2014, 36:99-103.

81. Xie ZB, Wang N, Wu WX, Le ZG, Yu XQ: Trypsin-catalyzed tandem reaction: one-pot synthesis of 3,4-dihydropyrimidin-2(1H)-ones by in situ formed acetaldehyde. J Biotechnol 2014, 170:1-5.

82. Jia B, Cheong GW, Zhang S: Multifunctional enzymes in archaea: promiscuity and moonlight. Extremophiles 2013, 17:193-203.

83. Mittag T, Kay LE, Forman-Kay JD: Protein dynamics and conformational disorder in molecular recognition. J Mol Recognit 2010, 23:105-116.

84. Skolnick J, Gao M: Interplay of physics and evolution in the likely origin of protein biochemical function. Proc Natl Acad Sci 2013, 110:9344-9349.

85. Hou L, Honaker MT, Shireman LM, Balogh LM, Roberts AG, Ng K, Nath A, Atkins WM: Functional promiscuity correlates with conformational heterogeneity in A-class glutathione S-transferases. J Biol Chem 2007, 282:23263-23274.

86. Honaker MT, Acchione M, Sumida JP, Atkins WM: Ensemble perspective for catalytic promiscuity: calorimetric analysis of the active site conformational landscape of a detoxification enzyme. J Biol Chem 2011, 286:42769-42776.

87. Honaker MT, Acchione M, Zhang W, Mannervik B, Atkins WM: Enzymatic detoxification, conformational selection, and the role of molten globule active sites. J Biol Chem 2013, 288:18599-18611.

88. Skopelitou K, Dhavala P, Papageorgiou AC, Labrou NE: A glutathione transferase from Agrobacterium tumefaciens reveals a novel class of bacterial GST superfamily. PLOS ONE 2012, 7:e34263.

89. Labrou NE: Affinity chromatography. In Methods for Affinity-Based Separations of Enzymes and Proteins. Edited by Gupta MN. Basel: Birkhauser Verlag; 2002:16-28.

90. Watson JD, Hopkins NH, Roberts JW, Steitz JA, Weiner AM: Molecular Biology of the Gene. fourthth edition. California: The Benjamin/Cummings Publishing Company Inc; 1987:1103-1124. 